\title{
Remote sensing of spectral signatures of tropospheric aerosols
}

\author{
M B Potdar ${ }^{1, *}$, S A Sharma ${ }^{1}$, V Y PARIKh ${ }^{1}$, P C S DeVara ${ }^{2}$, P E Raj ${ }^{2}$, Y K TiWARI ${ }^{2}$, \\ R S Maheskumar ${ }^{2}$, K K DAni ${ }^{2}$, S K SAhA ${ }^{2}$, S M Sonbawne ${ }^{2}$, Y JAYA RaO ${ }^{2}$ and \\ G PANDITHURAI ${ }^{2}$ \\ ${ }^{1}$ Space Applications Centre, Ahmedabad 380 015, India. \\ ${ }^{2}$ Indian Institute of Tropical Meteorology, Pune 411 008, India. \\ *e-mail: potdar51@hotmail.com
}

With the launch of the German Aerospace Agency's (DLR) Modular Opto-electronic Scanner (MOS) sensor on board the Indian Remote Sensing satellite (IRS-P3) launched by the Indian Space Research Organization (ISRO) in March 1996, 13 channel multi-spectral data in the range of 408 to $1010 \mathrm{~nm}$ at high radiometric resolution, precision, and with narrow spectral bands have been available for a variety of land, atmospheric and oceanic studies. We found that these data are best for validation of radiative transfer model and the corresponding code developed by one of the authors at Space Applications Centre, and called ATMRAD (abbreviated for ATMospheric RADiation). Once this model/code is validated, it can be used for retrieving information on tropospheric aerosols over ocean or land. This paper deals with two clear objectives, viz.,

(1) Validation of ATMRAD model/code using MOS data and synchronously measured atmospheric data, and if found performing well, then to

(2) derive relationship between MOS radiances and Aerosol Optical Thickness (AOT).

The data validation procedure essentially involves

- near-synchronous measurements of columnar aerosol optical thickness and altitude profiles of aerosol concentration using ground-based multi-filter solar radiometers and Argon-ion Lidar, respectively and

- computation of the top-of-the-atmosphere (TOA) radiances from a low reflecting target (near clear water reservoir in the present study) using the ATMRAD model.

The results show that the model performance is satisfactory and a relationship between the spectral parameters of MOS radiances and aerosol optical thickness can be established. In this communication, we present the details of the experiments conducted, database, validation of the ATMRAD model and development of the relationship between AOT and MOS radiance.

\section{Introduction}

Currently, satellite-based remote sensing instruments provide our best hope of obtaining the spatial and temporal coverage required for global change studies, particularly monitoring of atmospheric aerosols. Remote sensing of aerosols from satellites over the land and ocean is essen- tial to obtain the global aerosol budget to estimate the contributions of anthropogenic emissions to the aerosol budget and to the aerosol radiative forcing of climate (Charlson et al 1992; Andrae 1995). The available measurements are, in fact, insufficient to satisfy the increasing needs by the scientific community, of estimations of atmospheric aerosol content and type on global basis. Surface-based

Keywords. Land aerosols; spectral signatures; remote sensing; IRS-P3 MOS data. 
Table 1. Specifications of MOS-A/B/C sensor systems onboard IRS-P3 platform.

\begin{tabular}{|c|c|c|c|}
\hline Parameter & MOS-A & MOS-B & MOS-C \\
\hline Spectral range $(\mathrm{nm})$ & $755-768$ & $408-1010$ & $1500-1700$ \\
\hline No. of Channels & 4 & 13 & 1 \\
\hline Wavelength (nm) & $\begin{array}{c}756.7,760.6 \\
763.5,766.4 \\
\left(\mathrm{O}_{2} \mathrm{~A}-\text { Band }\right)\end{array}$ & $\begin{array}{c}408,443,485,520,570 \\
615,650,685,750,870 \\
1010,815,945 \\
\left(\mathrm{H}_{2} \mathrm{O} \text { vapour }\right)\end{array}$ & 1600 \\
\hline Spectral halfwidth (nm) & 1.4 & 10 & 100 \\
\hline FOV across track (deg) & 0.344 & 0.094 & 0.14 \\
\hline FOV along track (deg) & 13.6 & 14.0 & 13.4 \\
\hline Swath width $(\mathrm{km})$ & 195 & 200 & 192 \\
\hline No. of pixels/scan line & 140 & 384 & 299 \\
\hline Pixel size $\left(\mathrm{km}^{2}\right)$ & $1.57 \times 1.40$ & $0.520 \times 0.520$ & $0.520 \times 0.640$ \\
\hline $\begin{array}{l}\text { Measuring range } \\
L_{\min }\left(\mu \mathrm{W} / \mathrm{cm}^{2} . \text { nm.sr. }\right) \\
L_{\max }\left(\mu \mathrm{W} / \mathrm{cm}^{2} . \text { nm.sr. }\right)\end{array}$ & $\begin{array}{c}0.1 \\
40\end{array}$ & $\begin{array}{c}0.2 \\
65\end{array}$ & $\begin{array}{c}0.5 \\
18\end{array}$ \\
\hline$\Delta \mathrm{L} / \mathrm{L}(\%)$ & 0.3 & 1.0 & 2.0 \\
\hline Quantization level (bits) & 16 & 16 & 16 \\
\hline Signal/Noise ratio & $>330$ & $>100$ & $>50$ \\
\hline
\end{tabular}

measurements are limited in space and they are sparse. In this context, the Indian Remote Sensing Satellite (IRS-P3) which was launched in March 1996 under the ISRO-DLR collaborations forms an important contribution to this global effort. This satellite carries on board the DLR MOS and ISRO WiFS (Wide Field Sensor) systems for earth observations in addition to the X-ray Astronomy Payload for stellar burst detection.

Thus, MOS-A sensor system with four narrow spectral channels in $760 \mathrm{~nm} \mathrm{O}_{2}$-absorption band has been designed primarily for retrieving stratospheric aerosol optical thickness (AOT); while MOS-B with 13 narrow channels in the 408 to $1010 \mathrm{~nm}$ range is designed for retrieval of tropospheric AOT and ocean color mapping. The specifications of MOS sensors are given in table 1. These data have swath of about $200 \mathrm{~km}$. The spatial resolutions are about $1.5 \mathrm{~km}$ for MOS-A and 0.52 to $0.60 \mathrm{~km}$ in case of MOS-B and MOS-C data, respectively. The most important specification to be noted is the high precision of the measurements as reflected by the high signal-to-noise ratio achieved at even $L$ min, which is $>330$ and $>100$ in case of MOS-A and MOS-B data, and 16 bit radiometric quantization. With this type of highly precise data, the other applications of the data which can be taken up over land include vegetation mapping, growth assessment, and vegetation water stress detection specifically using MOS-C data. The availability of multi-spectral data in the wavelength region from $408 \mathrm{~nm}$ to $1010 \mathrm{~nm}$ with
$10 \mathrm{~nm}$ FWHM of MOS-B sensor over land offers the above potential applications. Also, the MOS-A and MOS-B data together have the potential for partitioning of total aerosol optical thickness into tropospheric and stratospheric components. For any of the above applications a pre-validated radiative transfer model is necessary. This forms one of the two objectives of this study, viz.,

(1) Validation of ATMRAD model/code using MOS-B radiances and synchronously measured atmospheric data, and if the model is found performing well then to

(2) derive relationship between spectral parameters, MOS radiances and AOT.

The satellite-observed MOS-B radiances over a fairly clear water reservoir are used in conjunction with the measured atmospheric aerosol parameters and ATMRAD model. The model details are published in Potdar $(1987,1990)$. Both the Lidar and sun photometric measurements are used to retrieve the aerosol number density altitude profile and spectral variation of AOT, respectively. The spectral AOT data are used to retrieve aerosol size distribution, which are used in the ATMRAD model to compute TOA outgoing radiance in the spectral channels of MOS-B for the sun-targetsensor geometry. The computed and MOS-B radiances are compared for validation of the model, and later to evaluate, in turn, aerosol properties over land surface from MOS radiances. Some of the early results obtained in this direction have been 
Table 2. The source of various aspects of ATMRAD model/code.

\begin{tabular}{ll}
\hline Data/Model/Formulations/Solutions & Source \\
\hline Atmospheric data & Valley (1965), McClatchey et al (1972) \\
\hline Solution of radiative transfer equation & Chandrasekhar (1960) \\
\hline Rayleigh/Mie scattering computations & McCartney (1976), van de Hulst (1957) \\
\hline Solar spectral irradiance & Neckel and Labs (1984) \\
\hline Aerosol models & McCartney (1976), Fisher (1970) \\
\hline Ozone, $\mathrm{H}_{2} \mathrm{O}$-vapour Abs. cross sections & McClatchey et al (1972), Chahine (1983) \\
\hline
\end{tabular}

reported elsewhere (Potdar et al 1998, 1999, 2001; Potdar and Devara 2000a,b, 2001). The present communication deals with the details of the measurements conducted, validation of the model/code and retrieval of AOT over land from the MOS-B data. In the present analysis 11 out of 13 channels data are used by excluding two water vapour absorption channels centered at 815 and $945 \mathrm{~nm}$.

\section{ATMRAD model description}

The ATMRAD model (Potdar 1987, 1990), which was developed and coded during 1984-86 time frame, is partially based on model equations given by McClatchey et al (1972) which was a basis of the LOWTRAN code (Kneizys et al 1983). The ATMRAD model/code improves upon the representation of the model atmosphere and the solar spectral profile. It also computes Mie and Rayleigh scattering phase functions and scattering, absorption and extinction efficiencies for a given complex refractive index of aerosols and the air. The single scattering albedo is then simply obtained by taking the ratio of scattering and extinction efficiencies. Thus, both the phase function and single scattering computation are built in the ATMRAD code. The sources of various data, model equations, and solution techniques adopted are given in table 2 .

The model/code attempts to simulate the radiation transfer process and hence, remote sensing process in the atmosphere as closely as possible. The multiple scattering effects are largely taken into account by representing the atmosphere stratified into 100 plane parallel layers; and all the physical parameters of gaseous and particulate components specified for each layer. The computations are performed for intensity of the direct solar radiation reaching each layer, scattered in satellite direction and further absorption and scattering in the remaining upper as well as lower layers of the atmosphere. The radiation scattered by the lower-most layer will undergo scattering by 99 layers above it before reaching the top of the atmosphere which is assumed to be $100 \mathrm{~km}$ thick. The spectral range of 250 to $3000 \mathrm{~nm}$ is representation by 127 sampled wavelength values so as to represent the most prominent features of the solar spectral radiance, absorption features of the prominent gaseous components of atmosphere, such as $\mathrm{O}_{2}, \mathrm{O}_{3}, \mathrm{~N}_{2}, \mathrm{CO}_{2}, \mathrm{H}_{2} \mathrm{O}$. The size range of 0.01 to $10 \mu \mathrm{m}$ of aerosol is sampled in to 32 values on $\log$ scale to represent the prominent features of various size distributions. All these features make the ATMRAD code more legible, easy to use and amenable to heuristic investigation and more compact compared to LOWTRAN. Unlike LOWTRAN, ATMRAD confines itself to reflective part of solar spectrum, i.e., 250 to $3000 \mathrm{~nm}$ range. Recently, Vermote et al (1997) have developed the simplified $6 \mathrm{~S}$ code for simulation for TOA radiances.

\section{Relevance of IRS-P3 MOS data to global change studies}

Aerosols play a wide range of roles in several branches of atmospheric science. Although aerosols have a very short residence time in the atmosphere as compared to time scales of climatic changes, the secular variations in the aerosol loading influence the climatic variations significantly. Due to the increased anthropogenic activities globally; without paying due attention to the fragile biosphere of the earth, the evaluation of activities lies at the core of human civilization. Thus, the present study eventually aims at the multi-dimensional mapping of aerosol characteristics from the satellite spectral signatures. This study has the following relevance to global change studies.

- Correction of remotely sensed data for retrieval of surface reflectance.

- Retrieval of water leaving radiances for ocean color mapping.

- Estimation of aerosol loading due to bio-mass burning.

- Effect of aerosols on cloud dynamics and earthatmosphere radiation balance.

- Effect on global warming/cooling. 
Table 3. Status of experimental observations.

\begin{tabular}{ccccc}
\hline Year & Satellite & Total no. of passes & Clear sky days & No. of useful days \\
\hline 1997 & IRS-P3 & 10 & 4 & 3 \\
\hline 1998 & IRS-P3 & 13 & 10 & 4 \\
\hline 1999 & IRS-P3 & 16 & 10 & 10 \\
\hline & Total & 39 & 24 & 17 \\
\hline
\end{tabular}

\section{Experimental sites}

The experimental sites, viz., the Khadakwasla and Mulshi water reservoirs near Pune, have been chosen as the experimental sites due to their fairly clear waters and their location being in close proximity of the Indian Institute of Tropical Meteorology (IITM), which is equipped with Lidar and multichannel sun photometer facilities for aerosol monitoring and characterization studies (Devara et al $1995 \mathrm{a}, \mathrm{b})$. The vertical profiles of aerosol number density were derived from Lidar sounding during early morning (pre-sunrise) and late evening (post sunset) period. The columnar AOT in the spectral range between 308 and $1060 \mathrm{~nm}$ were deduced by Langley plot method from solar irradiance measured using rotating filter radiometer during 1997 and 1998 and later using MicrotopsII sun and Ozone photometers (manufactured by Solar Light Co. USA) in 1999 on the days of IRSP3 satellite pass over experimental sites. However, as presented in table 3, good and reliable observations could be obtained on 17 days due to either unfavorable sky conditions or MOS data acquisition problems or both out of 39 days of measurements (table 3), even though we could get 24 clear sky days. The portable meteorological kits were also installed at the experimental sites for recording surface meteorological parameters such as wind speed and direction, temperature, relative humidity in order to examine their influence on AOT during the span of the day of measurement.

\section{Methodology}

The methodology consisted of mainly four components, viz.,

(i) deduction of AOT, aerosol size distribution and altitude profile,

(ii) ATMRAD model computation of expected TOA radiances from the reservoir waters for given atmospheric aerosol loading,

(iii) their comparison with MOS-B radiances for validation of the ATMRAD model/code, and

(iv) develop relationship between AOT and TOA radiance.
The various steps involved in the methodology followed are briefly indicated below.

\subsection{Atmospheric data processing}

(i) Deduce total optical thickness for the sun photometer channels from the Langley plot of a series of forenoon measurements of solar irradiance from the multichannel radiometer.

(ii) Compute the Rayleigh and Ozone optical thickness for tropical model atmosphere and subtract them from total optical thickness to obtain aerosol optical thickness (Devara et al 1995a,b). These steps (i) and (ii) are not required in case Microtops-II is used as it directly gives AOT.

(iii) As the altitude profile of the aerosols at the time of satellite pass (between 1030 and 1100 hrs IST) cannot be measured using Lidar, deduce the expected vertical distributions of aerosol number density at the time of satellite data acquisition from the morning and evening Lidar scatter intensity profiles. Here aerosol altitude profiles are used instead of columnar densities because of the requirement of the ATMRAD model/code. This gives power to the model/code to account for multiple scattering effects on computed TOA radiances and compute radiances at any desired altitude using aerosol altitude profile as input.

(iv) Assume bi-modal aerosol size distribution with anthropogenic component represented by modified Junge function (Junge, 1955 and King

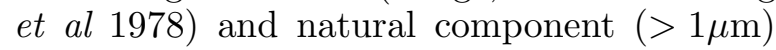
by normal function on log-normal scale. Compute altitude profiles mixing parameter and the resultant altitude profile to be used in the code to compute TOA radiances.

\subsection{Satellite data processing, validation and calibration of ATMRAD}

(i) Plug in the sun-target sensor geometry and the aerosol parameters to compute the expected TOA radiances from reservoir waters.

(ii) Compare the spectral channel-wise computed model radiances with the synchronously 


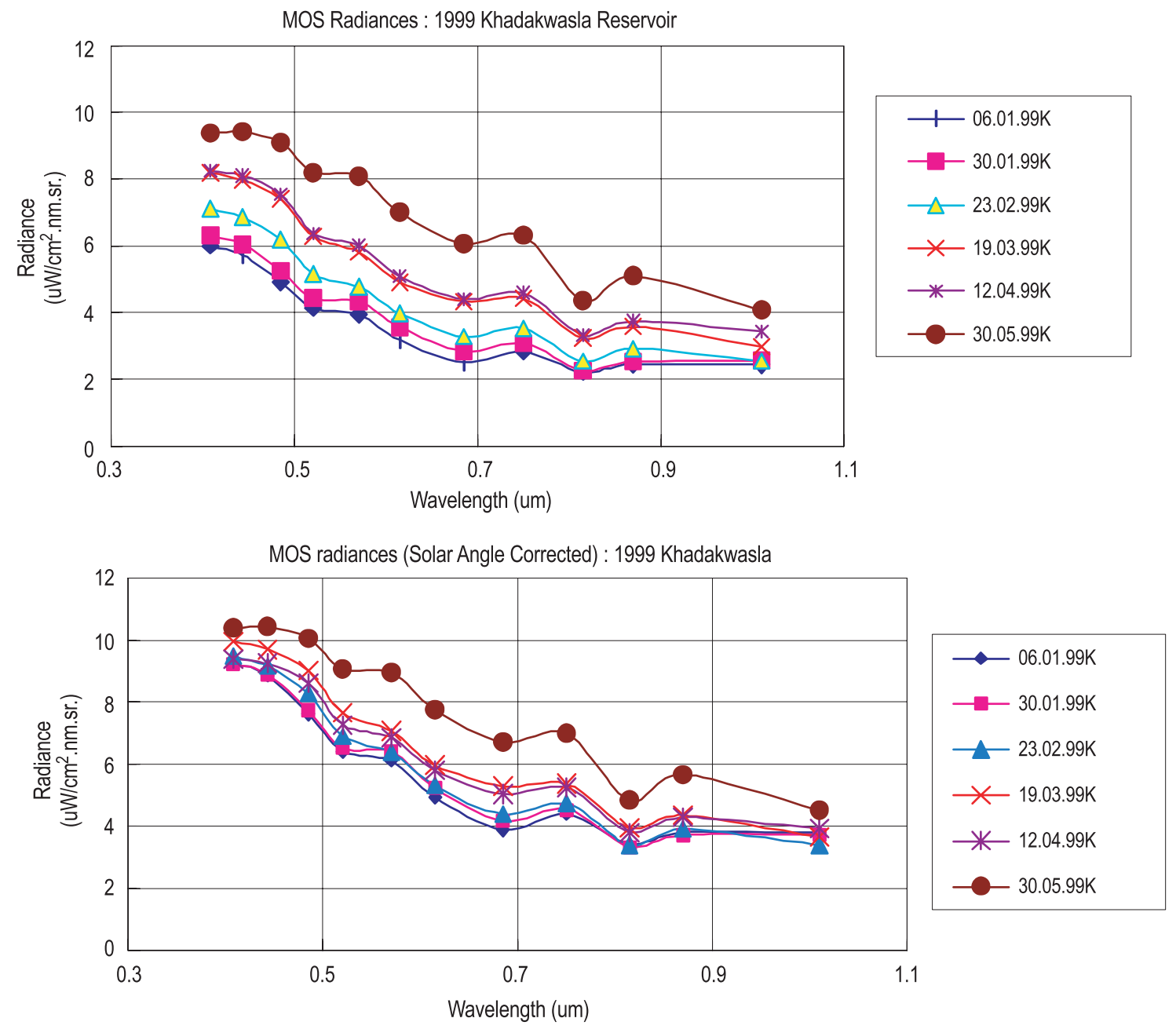

Figure 1. MOS-B radiance from Khadakwasla reservoir waters measured during IRS-P3 passes during 1999 measurement period.

acquired MOS-B radiance data to evaluate the model performance. The required quantities, like the single scattering albedo for given complex refractive index for the air and aerosols, both the Rayleigh and Mie scattering phase functions for the sun-target-sensor geometry and given aerosol size distribution function (described in the section 4.2 above) are computed using the Rayleigh and Mie scattering equations in the ATMRAD model/ code.

\subsection{Retrieval of aerosol parameters}

(i) Compute spectral indices and coefficients in the power law fitting of MOS-B radiances.

(ii) Compute angstrom exponent of aerosol optical thickness, total optical thickness and respective coefficients.

(iii) Establish relationships between indices and coefficients of MOS radiances and spectral AOT.

\section{Results and discussion}

The results obtained from the experiments conducted during three consequent years, i.e., 1997 through 1999 are presented and discussed in the following sub-sections.

\subsection{Satellite data characteristics}

The MOS radiance data were analyzed to examine the spectral variations of the radiance from the reservoir waters. Figure 1 shows the spectral characteristics of radiance with and without solar angle correction. The TOA radiances contain contributions from both molecular and aerosol scattering; but in the multiple scattering scenario, in any given elemental volume of the atmosphere, the Rayleigh scattered radiation undergoes Mie scattering and vice versa before emerging from the volume, resulting in TOA radiances to follow the power law in wavelength as each type of scatter- 
Table 4. Spectral analysis of IRS-P3 MOS-B radiance data of the reservoirs.

\begin{tabular}{|c|c|c|c|c|}
\hline Date & Spectral index & Coefficient & $\begin{array}{c}\text { Coefficient } \\
\text { (solar angle } \\
\text { corrected) }\end{array}$ & R-Square \\
\hline \multicolumn{5}{|c|}{ Khadakwasla reservoir } \\
\hline 06.01 .99 & 1.4798 & 1.6353 & 2.5309 & 0.95 \\
\hline 30.01 .99 & 1.4500 & 1.7995 & 2.6425 & 0.96 \\
\hline 23.02 .99 & 1.4644 & 2.0258 & 2.7050 & 0.96 \\
\hline 19.03 .99 & 1.3048 & 2.7124 & 3.2987 & 0.96 \\
\hline 12.04 .99 & 1.2723 & 2.8242 & 3.2183 & 0.95 \\
\hline 30.05 .99 & 1.1264 & 3.9953 & 4.4207 & 0.89 \\
\hline \multicolumn{5}{|c|}{ Mulshi reservoir } \\
\hline 18.02 .99 & 2.0236 & 1.3594 & 1.8636 & 0.97 \\
\hline 14.03 .99 & 1.8507 & 1.5458 & 1.9215 & 0.97 \\
\hline 07.04 .99 & 1.3274 & 2.9536 & 3.4098 & 0.96 \\
\hline 01.05 .99 & 1.1972 & 3.9944 & 4.4484 & 0.92 \\
\hline
\end{tabular}

Table 5. Spectral analysis of the optical thickness data.

\begin{tabular}{lllcccc}
\hline \multirow{2}{*}{$\begin{array}{l}\text { Date of } \\
\text { IRS-P3 Pass }\end{array}$} & $\begin{array}{c}\text { Aerosol optical thickness } \\
\text { Spectral } \\
\text { index }\end{array}$ & Coefficient & R-Square & $\begin{array}{c}\text { Spectral } \\
\text { index }\end{array}$ & Coefficient & R-Square \\
\hline \multicolumn{2}{l}{ Khadakwasla reservoir } & & & & & \\
\hline 06.01 .99 & 1.1339 & 0.0752 & 0.99 & 1.9619 & 0.0765 & 0.99 \\
\hline 30.01 .99 & 1.4205 & 0.0456 & 0.99 & 2.3258 & 0.0480 & 0.99 \\
\hline 23.02 .99 & 0.6164 & 0.1889 & 0.99 & 1.2058 & 0.1798 & 0.97 \\
\hline 19.03 .99 & 0.4044 & 0.3612 & 0.99 & 0.8188 & 0.3454 & 0.96 \\
\hline 12.04 .99 & 0.4624 & 0.3863 & 0.99 & 0.8328 & 0.3708 & 0.97 \\
\hline 30.05 .99 & 1.4257 & 0.0396 & 0.99 & 2.4082 & 0.0423 & 0.99 \\
\hline Mulshi reservoir & & & & & & 0.99 \\
\hline 18.02 .99 & 1.4138 & 0.0443 & 0.99 & 2.3484 & 0.0464 & 0.99 \\
\hline 14.03 .99 & 1.4119 & 0.0567 & 0.99 & 2.2187 & 0.0581 & 0.99 \\
\hline 07.04 .99 & 1.4312 & 0.0351 & 0.99 & 2.4769 & 0.0381 & 0.99 \\
\hline 01.05 .99 & 1.4183 & 0.0687 & 0.99 & 2.1188 & 0.0699 & \\
\hline
\end{tabular}

ing follows power law. Accordingly, it is seen from the figure that the spectral dependence is very well characterized by power law in the wavelength given by $R_{\lambda}=K_{r} \lambda^{-n}$. The radiances normalized for different solar zenith angle are also shown in figure 1. It is also seen that the spread in normalized radiances reduces. In fact, the $R^{2}$ values of the fit are greater than 90 per cent as shown in table 4 . The radiances were corrected for solar illumination by multiplying with the secant of the instantaneous solar zenith angle. In such a presentation, the overall variations in the data from one day to another could be largely due to varying atmospheric conditions.

\subsection{Aerosol data characteristics}

\subsubsection{Spectral variations}

Both the Rayleigh and Mie scatterings are individually power law dependent on wavelength. The Rayleigh scattering has power law dependence of -4 and Mie scattering has 0 to -2 dependence on wavelength. The aerosol optical thicknesses as well as the total optical thickness measured over the experimental sites shown in figure 2 are observed to follow to power law. The exponent, in the case of aerosol optical thickness, is called Angstrom Exponent, and that in the case of total optical thick- 

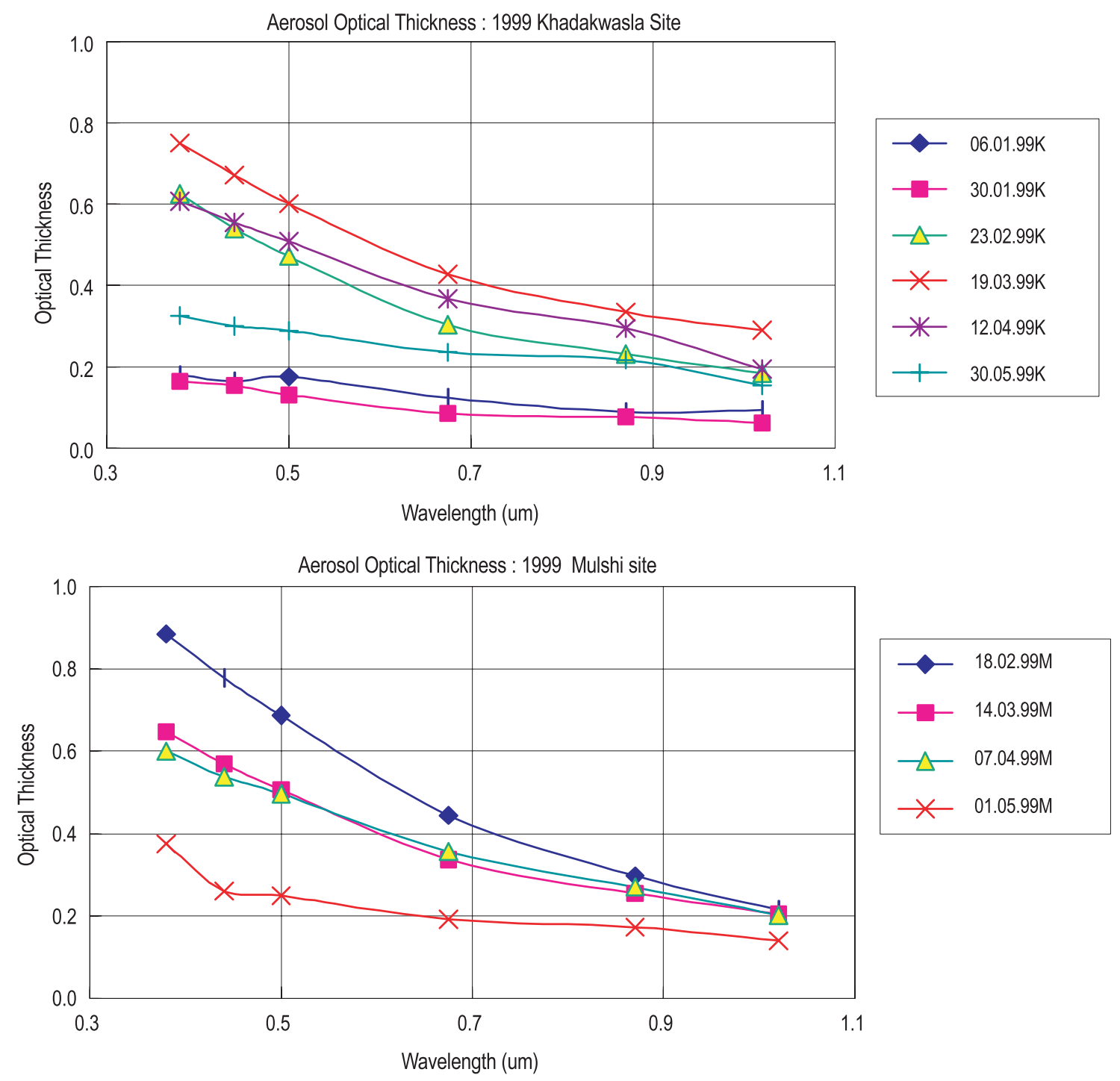

Figure 2. Measured aerosol optical thickness at Khadakwasla and Mulsi sites using Microtops-II sun photometers.

ness, is termed as $\tau_{\text {total }}$ exponent in this study. The data show that a power law equation, given by $\tau_{\lambda}=K_{r} \lambda^{-n}$, can be fit very well. The coefficients and exponents are given in figure 5 . The $R^{2}$ values of the fit are greater than 0.96 .

\subsubsection{Size distribution}

The spectral aerosol optical thickness data at six wavelengths of Microtops-II sun photometers are used for determining the aerosol size distribution by following the method of King et al (1978). Here, the size distribution is assumed to be at least bimodal in the 0.01 and $10 \mu \mathrm{m}$ range. As shown by King et al, their algorithm can be used for size distribution retrievals from AOT measurements at even as low as six wavelengths. The size distribution obtained is more or less similar to the modified Junge size distribution; when the minimum and maximum size values are fixed at $0.01 \mu \mathrm{m}$ and
$10 \mu \mathrm{m}$. The modified Junge size distribution parameters, thus computed, are presented in table 6 for the observations recorded on the satellite pass dates in 1999. The parameter XJ1 stands for the slope of natural aerosols in the modified Junge size distribution curve, and R02 stands for the peak size of the coarse aerosols of micron size particles, and FZ1 is the aerosol density mixing parameter to model the aerosol altitude distribution at the time of satellite overpass. The validity of the assumption of modified Junge size distribution is tested by a fit obtained between the computed and measured aerosol optical thickness at $500 \mathrm{~nm}$, $650 \mathrm{~nm}$ and $870 \mathrm{~nm}$. The 'Fit 2' corresponds to $500 \mathrm{~nm}$ and $870 \mathrm{~nm}$ wavelengths and 'Fit 3' to the fit at all the above three wavelengths. Thus, a larger value of 'Fit 2' and 'Fit 3' implies larger deviation of actual size distribution from the modified Junge size distribution. The computed and measured total optical thicknesses for all experi- 
Table 6. Parameters used in modelling size distribution and vertical profile of aerosols.

\begin{tabular}{lcccccc}
\hline $\begin{array}{c}\text { Date of } \\
\text { IRS-P3 pass }\end{array}$ & $\begin{array}{c}\text { XJ1 } \\
\text { (Slope })\end{array}$ & $\begin{array}{c}\text { R02 } \\
(\mu \mathrm{m})\end{array}$ & $\begin{array}{c}\text { FJ1 } \\
(x 10-3)\end{array}$ & Fz & Fit 3 & Fit 2 \\
\hline \multicolumn{2}{l}{ Khadakwasla site } & & & & & \\
\hline 06.01 .99 & 4.6 & 1.1 & 9 & 0.0 & 0.008 & 0.005 \\
\hline 30.01 .99 & 4.6 & 0.5 & 10 & 0.2 & 0.027 & 0.027 \\
\hline 23.02 .99 & 3.6 & 0.9 & 6 & 0.0 & 0.145 & 0.145 \\
\hline 19.03 .99 & 3.4 & 1.5 & 8 & 1.0 & 0.159 & 0.157 \\
\hline 12.04 .99 & 3.4 & 0.5 & 10 & 0.0 & 0.237 & 0.237 \\
\hline 30.05 .99 & 4.6 & 0.9 & 1 & 0.0 & 0.091 & 0.090 \\
\hline Mulshi site & & & & & & \\
\hline 18.02 .99 & 3.6 & 0.5 & 10 & 0.8 & 0.223 & 0.223 \\
\hline 14.03 .99 & 3.8 & 0.5 & 7 & 1.0 & 0.113 & 0.112 \\
\hline 07.04 .99 & 3.4 & 0.5 & 8 & 1.0 & 0.128 & 0.127 \\
\hline 01.05 .99 & 4.4 & 0.9 & 5 & 0.4 & 0.012 & 0.002 \\
\hline
\end{tabular}

mental dates in 1999 at the Khadakwasla site are compared in figure 3 . In general, there is good agreement between computed and measured optical thickness; depending on the validity of the assumed modified Junge size distribution function. On 30th May 1999, the sky was partially cloudy and the atmosphere was unstable. Even though the sky was cloudy, we could make sun photometric measurements through cloud windows. The computed optical thickness are lower than the measured at all wavelengths.

\subsubsection{Altitude profile}

The importance of using altitude profile of aerosol density instead of columnar density is already discussed above. Particularly, it helps in accounting for the multiple scattering effects. The Lidar system used in the present study has been operated in bi-static configuration at a wavelength of $514.5 \mathrm{~nm}$, and is powerful enough for sounding of the atmosphere up to $7 \mathrm{~km}$ altitude with laser output power of $400 \mathrm{~mW}$. The Lidar description and methodology followed for computing the aerosol number density are given in Devara and Raj (1987, 1993). In the computation of aerosol concentration, the power law distribution given by McClatchy et al (1972) for aerosol sizes ranging from $0.1 \mu \mathrm{m}$ to $10 \mu \mathrm{m}$, which is representative of the conditions of the experimental station is used. The most important parameter is the slope in the 0.1 to $1.0 \mu \mathrm{m}$ size range and it is required to be known a priori. As the Lidar sounding, at present, can be performed only during night time, the experiments were conducted about one hour before sunrise and after sunset on the days of the satellite overpasses. The radiometric observations were carried out near- synchronous to satellite overpass. Therefore, the slope computed from the radiometer data is used in the computation of the aerosol number density. Whenever the altitude profiles are contaminated by the presence of clouds, they are removed by suitable standard techniques and then the smoothened profile is used in the model. As the clear-sky aerosol density at higher altitudes is very less, it is assumed to be zero in the present study. The typical altitude profiles are shown for four dates in figure 4 . These were the days of stable atmospheric conditions. It is seen that there is not much difference between the morning and evening profiles.

\subsection{ATMRAD model validation}

The ATMRAD model/code requires the altitude profile as input. As the Lidar measurements cannot be made in the day time, a numerical approach, briefly described below, is followed to approximate profile at the time of satellite pass, which is built in the model/code.

Assuming that the morning altitude profile transcends into evening profile, the altitude profile at any intermediate time can be represented as a linear combination of the two profiles as

$$
N z=F z * N z(M, z)+(1-F z) * N z(E, z)
$$

where $0.0 \leq F z \leq 1.0$ and $N z(M, z)$ and $\mathrm{Nz}(\mathrm{E}, \mathrm{z})$ stand for aerosol number density at altitude $z$ in the early morning $(M)$ and early evening $(E)$. Actually, $F z$ is a function of $z$, and there is no way to measure it. Hence, $F z$ is assumed to be constant in the present study. The accepted value is the one with which the computed aerosol optical thickness at the Lidar wavelength of $514.5 \mathrm{~nm}$ using ATM- 

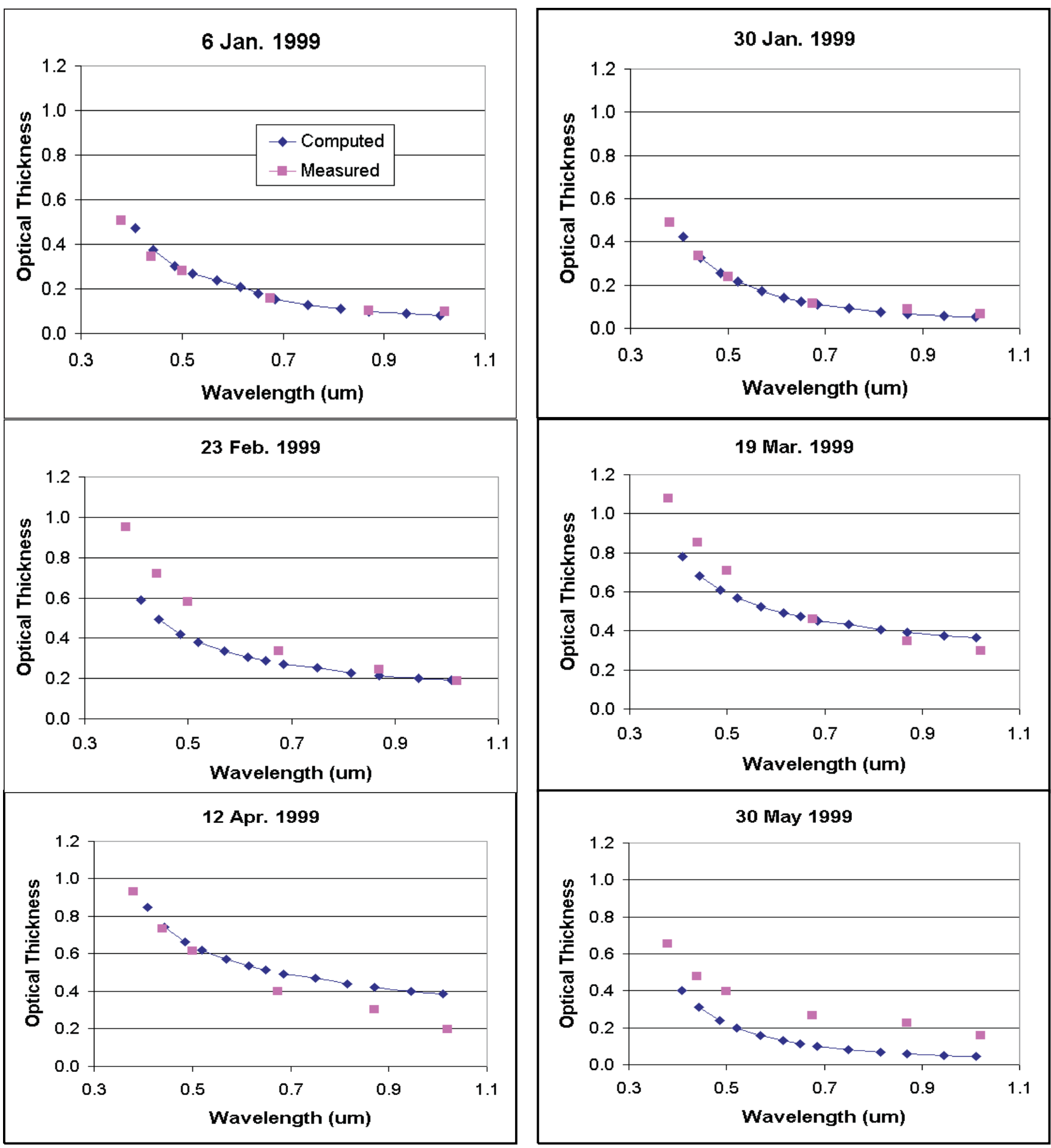

Figure 3. Comparison of measured and computed total optical thickness (Khadakwasla site).

RAD model agrees with that from the radiometer. The computed values of $F z$ are presented in table 6 . The higher the value of $F z$, the more the profile resembles the morning profile.

The ATMRAD model-computed TOA radiances for the sun-target-sensor geometry and the prevailing atmospheric conditions at the time of the satellite overpass and the MOS radiances from the Khadakwasla reservoir waters are compared in figure 5 . The comparison shows, by and large, good agreement. However, the minor deviations observed could be attributed mainly to differences in the assumed and actual water reflectance. The agreement on 30th May 1999 is poor due to the prevailing unstable sky conditions.

Though the model/code accounts for the multiple scattering effects, the diffuse component of the solar irradiance on the surface is not considered. And also, the adjacency effect on the reflected radiance is not considered. These factors may also lead 

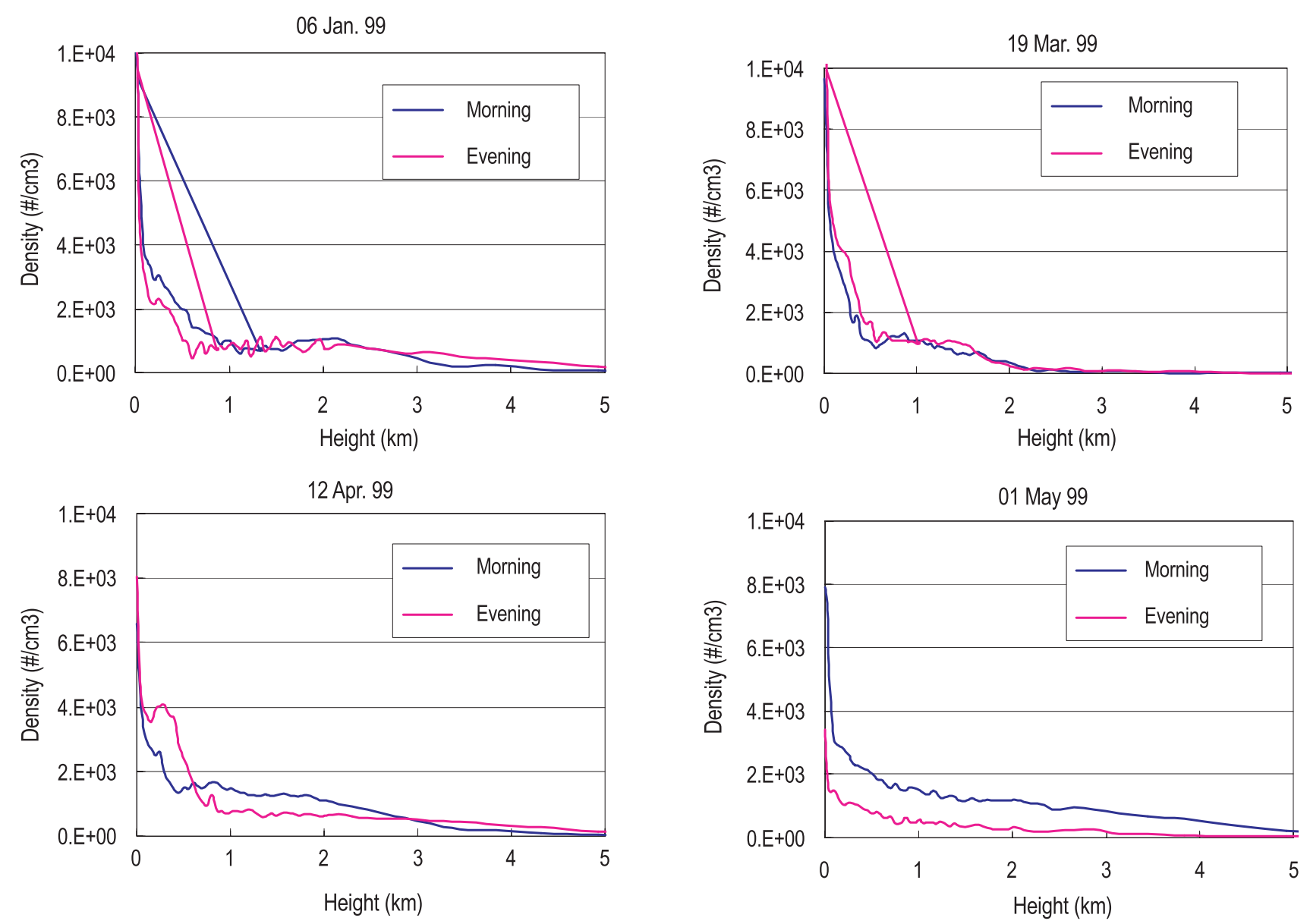

Figure 4. Altitude profile of aerosol number density obtained from LIDAR data.

to imperfect agreement between the computed and MOS radiances from the reservoir water. Here we look for the broad and overall agreement only. Such deviations between the modeled and observed radiances could be due to

- inadequacy in the simulation of radiative and scattering processes,

- assumed water reflectance profiles, and

- variation in actual reflectance of reservoir waters during the course of the experimental period, which stretches from January through May.

Moreover, the model uses typical hemispherical spectral reflectance of clear water lakes (Clarke et al 1970). The broad agreement seen in figure 5 between MOS and computed radiances is considered as satisfactory for validation of the ATMRAD model.

\subsection{Retrieval of aerosol parameters}

The usefulness of MOS data for retrieval of aerosol parameters is investigated using the type of relationships the MOS radiances and optical thickness exhibit. In this study, it is found that the MOS radiances as well as the optical thickness show power law dependence on wavelength, $\lambda$ (expressed in $\mu \mathrm{m})$, which is given by

$$
R_{\lambda}=K_{r} \lambda^{-n}, \quad \text { and } \quad \tau_{\lambda a}=K_{a} \lambda^{-m} .
$$

Here the subscripts $r$ and $a$ stand for radiance and aerosol, respectively, and ' $\mathrm{K}$ 's stand for corresponding coefficients. If such relationships exist, then they imply the following relationship between radiance and optical thickness

$$
\left(R_{\lambda} / R_{\lambda r}\right)^{m}=\left(\tau_{\lambda} / \tau_{\lambda r}\right)^{n} .
$$

From equation (2) we can write

$$
\tau_{\lambda}=\tau_{\lambda r}\left(R_{\lambda} / R_{\lambda r}\right)^{m / n} .
$$

For determining $\tau_{\lambda}$, the $\tau_{\lambda r}, R_{\lambda r}$ and the ratio $(m / n)$ are required to be known. Here, $\lambda r$ stands for reference wavelength. For computation purposes, we consider $\lambda r$ to be $1 \mu \mathrm{m}$. The aerosol optical thickness and radiance at reference wavelength can be deduced knowing the radiance at the corresponding wavelength.

An equation similar to (4a) above can be written for total optical thickness, viz., 

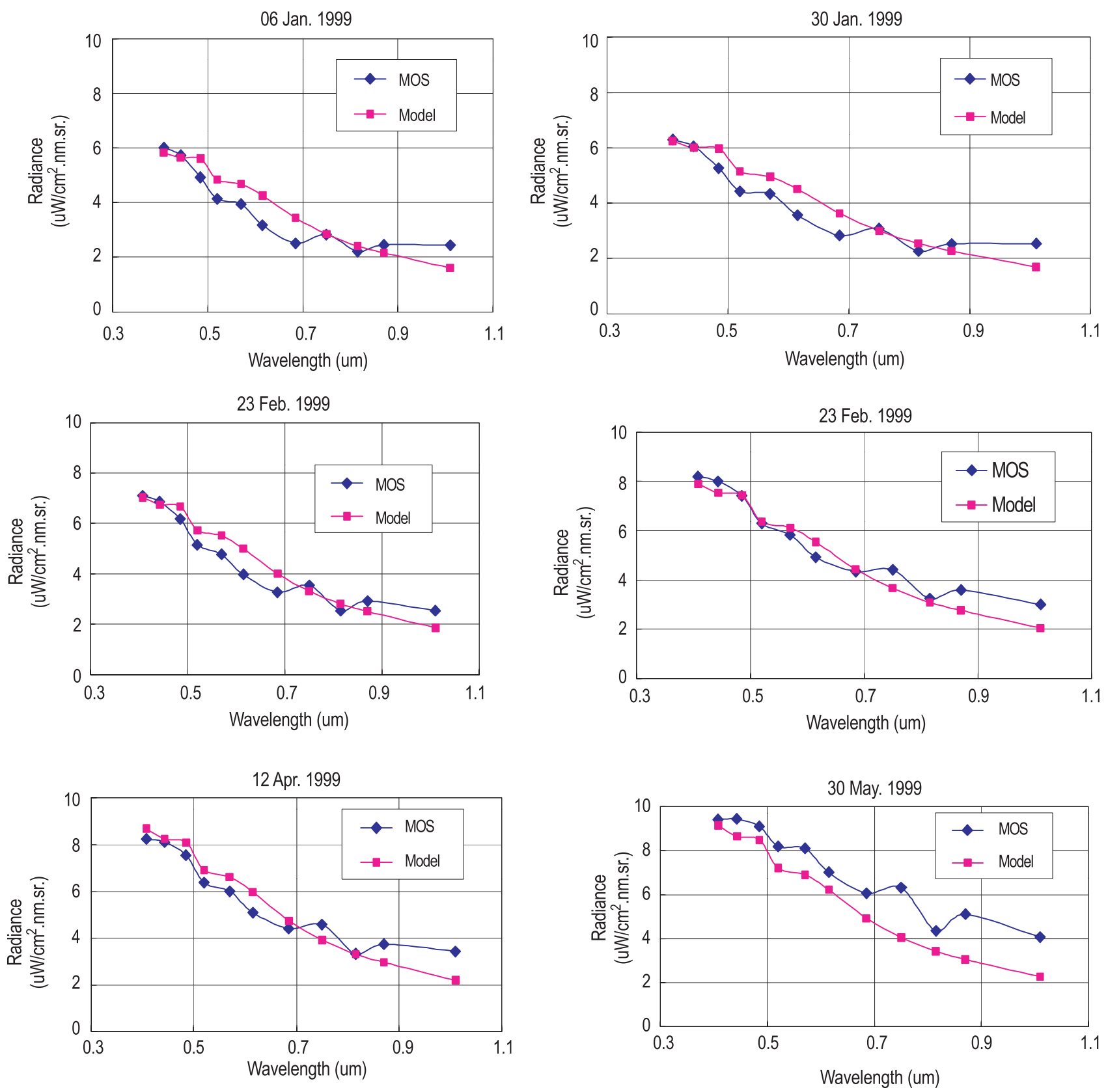

Figure 5. The validation of ATMRAD model by comparing the TOA MOS-B radiance from Khadakwasla reservoir waters and model computed radiance.

$$
T_{\lambda}=T_{\lambda r} \cdot\left(R_{\lambda} / R_{\lambda r}\right)^{M / n}
$$

where $M$ stands for spectral index in relationship of total optical thickness with wavelength.

From the data collected for all the three years of observations, it is found that majority of the days had atmospheric transmittance in a narrow range while solar illumination conditions differed due to varying solar zenith angle. Advantage is taken of these data sets to validate the dependence of ATMRAD model-derived path radiance on solar zenith angle and to evolve a suitable equation for estimating aerosol optical thickness as a function of wavelength.
From the computations of ATMRAD as well as other models, it is known that the path radiance is a non-linear function of solar zenith angle ranging from zero to 90 degrees for constant atmospheric conditions. The non-linearity decreases at longer wavelengths compared to that at shorter wavelengths. Figure 6 shows computed path radiance (solid line) and deduced path radiances (filled circles) for the days of IRS-P3 passes over the experimental sites. The model computations show that within the narrow range of solar zenith angle $\left(Z_{s}\right)$ from 25 to 55 degrees, and at longer wavelengths, the path radiance shows less non-linear dependence. Depicted in this figure are the path 


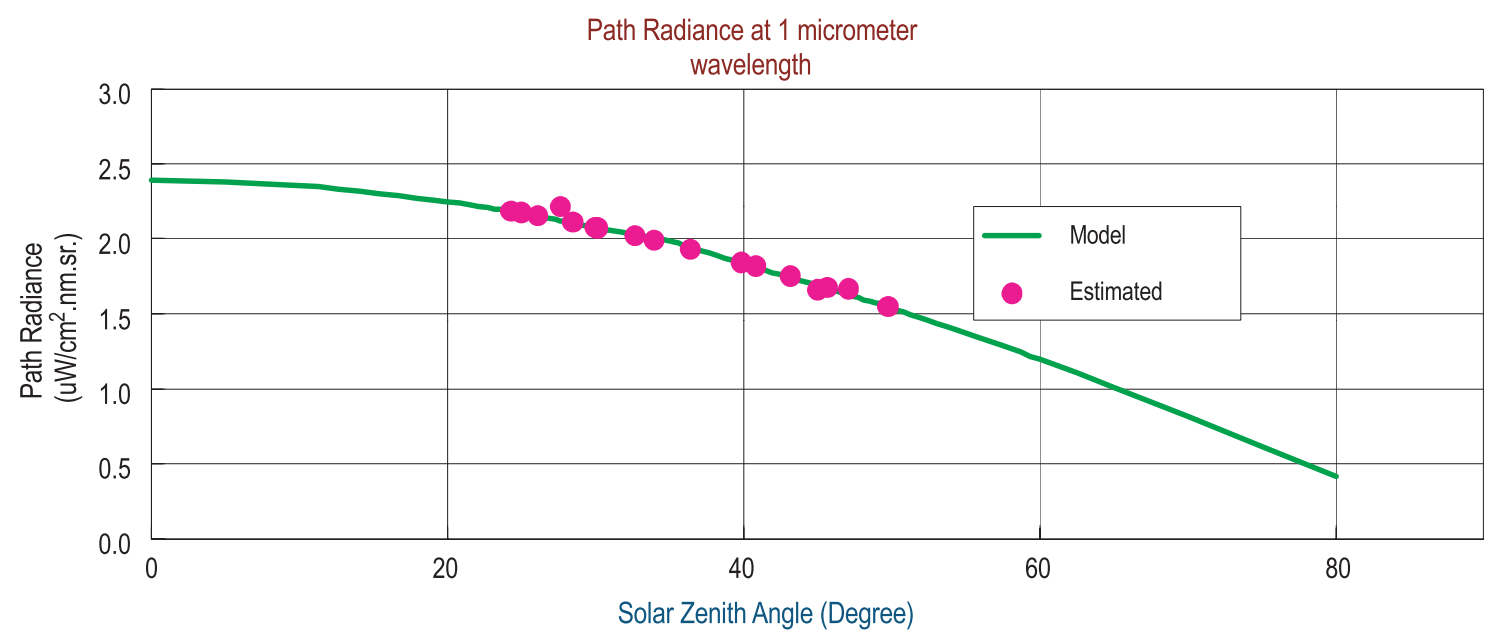

Figure 6. The comparison of ATMRAD model computed path radiance and deduced path radiance from MOS data.

Table 7. Computed solar angle corrected path radiances, aerosol and total transmittances and indices ratio for the dates of passes in 1999, 1998 and $199^{\prime 2}$ at $\lambda=1 \mu \mathrm{m}$.

\begin{tabular}{|c|c|c|c|c|c|c|c|c|}
\hline Year & Quantity & $\begin{array}{l}\text { Path } \\
\text { radiance }\end{array}$ & $\begin{array}{l}\text { Water } \\
\text { body } \\
\text { radiance }\end{array}$ & $\tau_{\text {aero }}$ & $\tau_{\text {total }}$ & $\begin{array}{l}\text { Aero. } \\
\text { trans. }\end{array}$ & $\begin{array}{l}\text { Total } \\
\text { trans. }\end{array}$ & $\begin{array}{c}\text { Indices } \\
\text { ratio }\end{array}$ \\
\hline \multirow[t]{3}{*}{1999} & Mean & 2.405 & 3.177 & 0.053 & 0.059 & 0.933 & 0.925 & 0.912 \\
\hline & Std. dev. & 0.018 & 0.827 & 0.015 & 0.015 & 0.023 & 0.029 & 0.198 \\
\hline & $\mathrm{CV}(\%)$ & 0.754 & 26.015 & 29.308 & 25.796 & 2.518 & 2.551 & 21.691 \\
\hline \multirow[t]{3}{*}{1998} & Mean & 2.410 & 2.933 & 0.057 & 0.0634 & 0.933 & 0.926 & 0.826 \\
\hline & Std. dev. & 0.036 & 0.602 & 0.010 & 0.010 & 0.014 & 0.0139 & 0.315 \\
\hline & $\mathrm{CV}(\%)$ & 1.495 & 20.530 & 18.122 & 15.935 & 1.483 & 1.496 & 38.166 \\
\hline \multirow[t]{3}{*}{1997} & Mean & 2.392 & 3.751 & 0.024 & 0.031 & 0.970 & 0.962 & 1.035 \\
\hline & Std. dev. & 0.033 & 0.273 & 0.005 & 0.005 & 0.003 & 0.003 & 0.264 \\
\hline & $\mathrm{CV}(\%)$ & 1.397 & 7.274 & 18.999 & 15.358 & 0.351 & 0.286 & 25.540 \\
\hline \multirow[t]{3}{*}{ All } & Mean & 2.404 & 3.196 & 0.049 & 0.055 & 0.941 & 0.934 & 0.908 \\
\hline & Std. dev. & 0.030 & 0.684 & 0.017 & 0.017 & 0.022 & 0.022 & 0.269 \\
\hline & $\mathrm{CV}(\%)$ & 1.248 & 2.140 & 34.694 & 30.909 & 2.238 & 2.355 & 29.626 \\
\hline
\end{tabular}

Radiance is expressed in $\left(\mu \mathrm{W} / \mathrm{cm}^{2} . n m . s r.\right)$.

radiances for an atmosphere with aerosol optical thickness in the range of $0.049 \pm 0.017(33 \%)$ which is typical of clear atmospheric conditions near Pune. Based on this observation, the path radiance, and the total as well as aerosol optical thickness are computed along the path of incident solar radiation. The salient results of these computations are presented in table 7 . The transmittances given in the table are for the total atmospheric path traced by solar rays before reaching the satellite sensor for the prevailing solar zenith angle. The results show that the computed radiances as well as transmittances are fairly constant for most of the clear atmospheric conditions around Pune. The coefficients of variation (CV in \%) are 1.248, 2.140, 2.338 and 2.355 for path radiance, water body radiance and for aerosol and total transmittances, respectively.

The $(\mathrm{m} / \mathrm{n})$ ratio is of the order of $0.908 \pm 0.269$ (29.63\%). Similar computations (not shown in the table above) were performed for ratio of indices of total optical thickness to radiance. This ratio also shows uncertainty of 33 per cent and is equal to $1.532 \pm 0.504(33 \%)$. Substituting these values of constants, the equation (4a) takes the form

$$
\tau_{\lambda}=0.049^{*}\left[R_{\lambda} /\left(3.196^{*} \cos Z_{s}\right)\right]^{0.908 \pm 0.269} .
$$

Here, $Z_{s}$ stands for solar zenith angle. Mainly the relationships between indices of MOS data and optical thickness data are important, as they can be useful to deduce optical thickness from MOS indices and coefficients. It seems that there do exist 

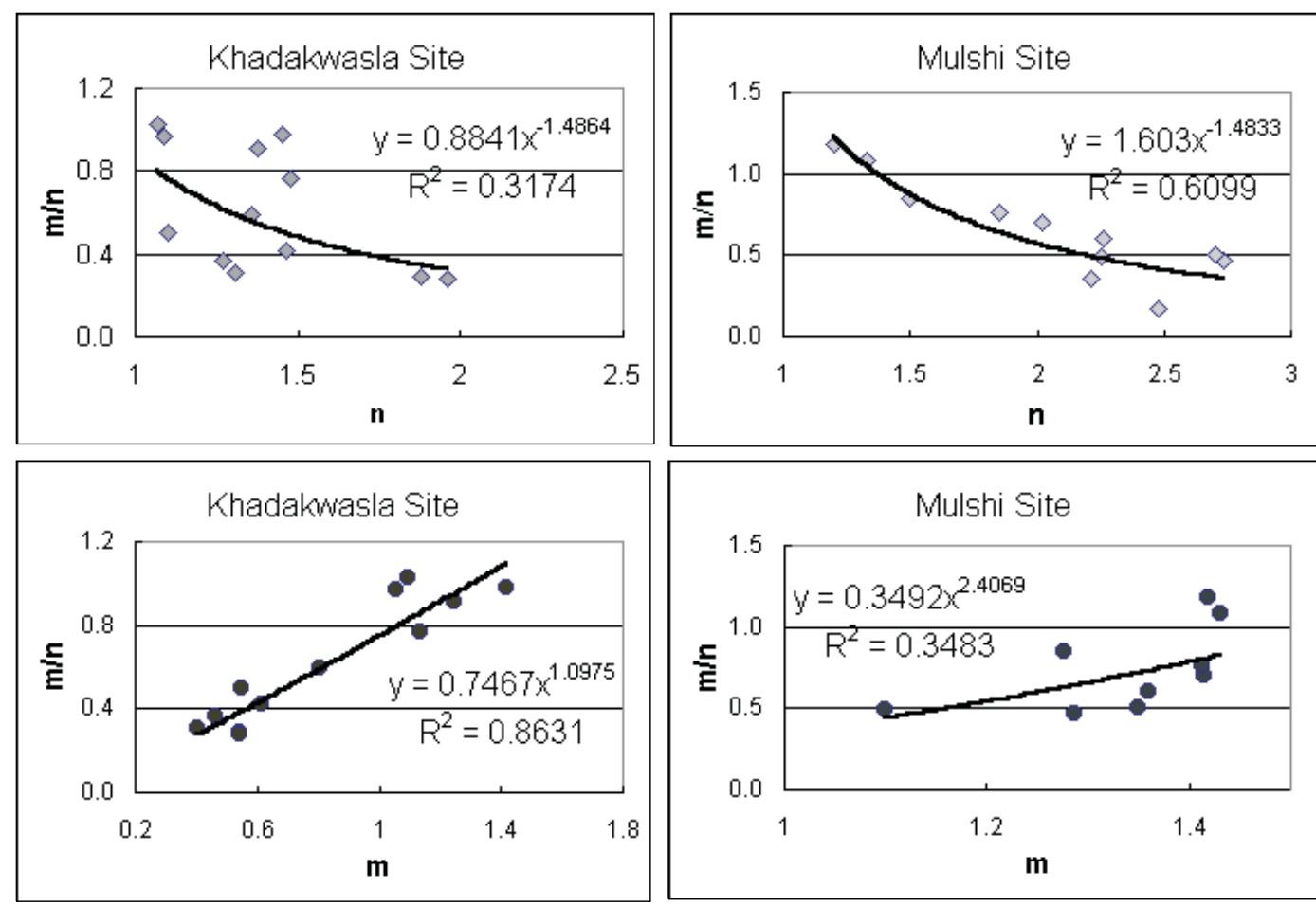

Figure 7. The relationships between the spectral indices of water radiance and aerosol optical thickness.

such relationships, but here the numbers of data points are too small to arrive at any definite conclusion. The results indicate that the MOS data do show potentiality for aerosol determination.

From figure 7, where the indices of water radiance and optical thickness are plotted, it is clear that there are well established relationships among the $m / n$ and $M / n$ ratios and $n, m$ and $M$ parameters. These relationships among various parameters at both the water reservoir sites considered in the present study are as follows.

Khadakwasla site:

$$
\begin{array}{ll}
m / n=0.8841 \mathrm{n}^{-1.4864} & \left(R^{2}=0.32\right) . \\
m / n=0.7467 \mathrm{~m}^{1.0794} & \left(R^{2}=0.86\right) .
\end{array}
$$

Mulshi site:

$$
\begin{array}{ll}
m / n=1.6030 \mathrm{n}^{-1.4833} & \left(R^{2}=0.61\right) . \\
m / n=0.3492 \mathrm{~m}^{2.4069} & \left(R^{2}=0.35\right) .
\end{array}
$$

It is observed that the above relationships are significant when the range of parameter value is large. There are well defined relationships between spectral indices (in power law) and their ratios. These relationships can be used for retrieving spectral dependence and hence aerosol size distribution parameters.

The aerosol size distributions at Khadakwasla were found to be mostly bi-modal in nature, indicating the influence of anthropogenic activities, which is consistent as this site is situated near the outskirts of Pune city. The size distributions at the Mulshi reservoir were mostly unimodal, as this place is about $50 \mathrm{~km}$ away from Pune city and free from any industrial pollution. Therefore, the ranges of parameters were in general, narrow in the vicinity of Khadakwasla reservoir than that in the vicinity of Mulshi reservoir.

\section{Conclusions}

The experiments and data analyses carried out for the satellite data indicate the capability of MOS spectral signatures for aerosol parameter retrieval as well as ATMRAD model calibration. Some of the conclusions drawn from these studies are as follows:

- The ATMRAD model performance is largely satisfactory.

- The TOA path radiance and water radiances as well as optical thickness follow spectral power law dependence as seen from high $R^{2}$ of the least square fittings in these cases. Over ocean also, this power law dependence is found to be followed. It only shows that the coarse mode component forms a minor fraction of the total number of particles both over the land and ocean.

- The solar angle corrected TOA radiance and optical thickness at $1 \mu \mathrm{m}$ exhibit well defined values, whereas the spectral indices ratios show larger variance. 
- There are nearly well defined relationships between spectral index and coefficients of the TOA radiances of water bodies and aerosol and total optical thickness.

\section{Acknowledgements}

We are thankful to the Programme Management Board of ISRO-GBP for the encouragement and support. This work is funded by the Department of Space (Govt. of India) under ISRO-Geosphere Biosphere Programme.

\section{References}

Andrae M O 1995 Climate effects of changing atmospheric aerosol levels, In: World's Survey of Climatology (ed) A Henderson-Sellers (Elsevier) 341-392

Chandrasekhar S 1960 Radiative transfer; London (Oxford: Oxford University Press)

Chahine M T 1983 Interaction mechanisms within the atmosphere; In: Manual of Remote Sensing Vol. 1, II Ed.; (American Society of Photogrammetry, USA)

Charlson R J, Schwartz S E, Hales J M, Cess R D, Coakley Jr. J A, Hansen J E and Hoffmann D J 1992 Climate forcing by anthropogenic aerosol; Science $\mathbf{2 5 5} 423-430$

Clarke G L, Ewing G C and Lorenzen C J 1970 Spectra of back scattered light from the sea obtained from aircraft as a measure of chlorophyll concentrations; Science $\mathbf{1 6 7}$ 1119-1121

Devara P C S and Raj P E 1987 A bistatic lidar for aerosol studies; IEEE Technical Review 4 412-415

Devara P C S and Raj P E 1993 Lidar measurements of aerosols in the tropical atmosphere; Advances in Atmospheric Science 10 365-378

Devara P C S, Raj P E, Sharma S and Pandithurai G 1995a Real-time monitoring of atmospheric aerosols using computer controlled lidar; Atmospheric Environment 29 2205-2215

Devara P C S, Raj P E, Pandithurai G and Sharma S 1995b A high spectral resolution radiometer for atmospheric monitoring; Journal of Instrumentation Society of India 25 142-154

Fisher K 1970 Measurements of absorption of visible radiation by aerosol particles; Atmospheric Physics 43244

Junge C E 1955 The size distribution and aging of natural aerosols as determined from electrical and optical data on the atmosphere; J. Meteorol. 12 13-25

King M D, Byrne D M, Herman B M and Reagan J A 1978 Aerosol size distribution obtained by inversion of spectral optical depth measurements; J. Atmos. Sci. 35 2153-2167

Kneizys F X, Shettle E P, Gallexy W O, Chetwynd J H, Abreu L W, Selby J E A, Cough S A and Fenn R W 1983 Atmospheric transmittance/radiance: computer code LOWTRAN 6; Air Force Geophysical Laboratory, Hanscom Air Force Base, Massachusetts, USA
McClatchey R A, Fenn R W, Selby J E A, Volz F E and Garing J S 1972 Optical properties of the atmosphere; AFCRL-72-0497, Air Force Cambridge Research Laboratories, Bedford

McCartney E J 1976 Optics of the atmosphere: Scattering by molecules and particles (John Wiley and Sons)

Neckel H and Labs D 1984 The solar radiation between 3300 and 12500 Angstroms; Solar Physics 90 205-258

Potdar M B 1987 Quasi-simple model of radiation transfer in the earth's hazy atmosphere for correction of remotely sensed data; Scientific Note: SAC/RSAG/LRD/01/87, Space Applications Centre, Ahmedabad

Potdar M B 1990 Modelling of radiation transfer in earth's hazy atmosphere and calculation of path radiances in IRS LISS-I Bands; Journal of the Indian Society of Remote Sensing, $18465-75$

Potdar M B, Sharma S A, Devara P C S,. Raj P E, Pandithurai G, Maheskumar R S and Dani K K 1998 ATMRAD model calibration, retrieval of aerosol optical thickness and atmospheric factors from IRS-P3 MOS Data; Scientific Note, SAC/RSAG/LRD/01/87, Space Applications Centre, Ahmedabad

Potdar M B, Sharma S A, Devara P C S, Raj P E, Pandithurai G, Maheskumar R S and Dani K K 1999 Retrieval of aerosol optical thickness and atmospheric correction factors from IRS-P3 MOS Data; In: Proc. ISRS National Symposium on Remote Sensing Applications for Natural Resources: Retrospective and Perspective, Bangalore, 19th-21st January 1999 526-529

Potdar M B and Devara P C S 2000a Atmospheric aerosol loading over land from IRS-P3 MOS sensor data; In: "Book of Abstracts of the ISRO Chairman's review of ISRO-GBP Projects" and the 3rd Workshop on Scientific Results from ISRO Geosphere Biosphere Programme, 3rd-4th October 2000, ISRO HQ, Bangalore

Potdar M B and Devara P C S 2000 Spectral characterization of optical thickness over land from IRS-P3 MOS-B sensor data; In: IGBP in India 2000: A Status Report on Projects, compiled and edited by the Indian National Committee for the International Geosphere-Biosphere Programme, 1997-2000, Verba Network Services, Bangalore, 206-211

Potdar M B and Devara P C S 2001b Land aerosol characterization from satellite data; In: Proc. of WG-II on Atmospheric Chemistry, Aerosols and Global Change Meeting on 20th-21st December 2001, SPL, VSSC, Trivandrum $37-40$

Potdar M B, Parikh V Y, Sharma S A, Devara P C S, Raj P E, Pandithurai G, Maheskumar R. and Dani K K 2001 Characterization of land aerosols using IRS-P3 MOS Sensor Data; SAC Director's review of ISRO-GBP projects at SAC, 31st July 2001

Valley S L (ed.) 1965 Handbook of Geophysics and Space Environment; (New Jersey: McGraw-Hill) USA

Van de Hulst H C 1957 Light scattering by small particles (New York: Wiley) USA

Vermote E F, Tanre D, Deuze J L, Herman M and Morcrette J 1997 Second simulation of the satellite signal in the solar spectrum, 6S: An Overview; IEEE. Transactions on Geoscience and Remote Sensing 35 675-686 